\title{
Transactions of Tianjin University: Join Us to Step up to the Next Generation of Sustainable Energy
}

\author{
Jinlong Gong ${ }^{1}$
}

Published online: 21 January 2020

(c) The Author(s) 2020

Due to a steady increase in world's population and huge demands of fossil fuels and its products, the global energy crisis has become more and more visible as the biggest challenge that impedes the sustainable development of humanity. As a result of advances in industry and technology and various forms of pollution from anthropogenic activities, our Earth has taken a great toll with massive emission of green house gases, causing the rise of sea levels, deforestation and extreme weather. Thus, to address climate change and seek harmonious development with environment is the primary task of scientists and policy makers; therefore, the research for clean and sustainable energy has seen explosive growth. With the rapid development of solar power, hydrogen energy, biofuels, etc., breakthrough in generating and storage of energy has driven the industry and technology to a new era. The modern society started to embrace the captivating technology of hydrogen vehicle, low energy housing and renewable heat. Energy-related topics attract enormous attentions from governments, societies and even investment.

To meet the growing demand on sustainable energy resources, scientists all over the world are now making a concerted effort in the innovation of new and advanced technologies, aggressive energy policies, action and planning activities. At the policy level, plenty of policy instruments are used to lead economic activity toward environmental sustainability, such as regulation, subsidies and tax incentives. Efforts are now putting on to resolve the barriers of commercial production based on sustainable energy and to get out of a predicament of environment and sustainability. As the main force to promote green energy revolution, researchers from different fields have realized that developing novel and reliable materials and devices is essential to improving the efficiency and safety of new energy as well as reducing environmental impacts. The unremitting efforts of cross-field research works have broadened the academic horizon and brought together chemistry, materials science, applied and theoretical physics, fabricating new materials and designing manufacturing methods or reviving present materials for brand new applications for next-generation energy technology.

The Transactions of Tianjin University (ISSN 1006-4982) is an academic journal published by the Springer Nature Group. The theme of our journal is to publish high-quality, cutting-edge research in natural science and engineering, particularly focusing on energy-related technologies. The journal will serve as a high-quality platform for researchers working in a wide variety of scientific areas with interests in energy-related fields, such as solar energy and photovoltaics, energy storage and conversion materials, batteries and supercapacitors, $\mathrm{CO}_{2}$ conversion and storage, new strategies for the clean utilization of coal and oil and so on. Transactions of Tianjin University is an international, peer-reviewed, interdisciplinary journal, which publishes a full mix of research article types, including letters, articles, perspectives, reviews and viewpoints with online publications accessed through SpringerLink (https://link.springer. com/journal/12209).

The editor in chief of Transactions of Tianjin University is Prof. Jinlong Gong, Cheung Kong Chair Professor and Vice President of Tianjin University, who is one of the global highly cited researchers in both 2018 and 2019. With a group of experienced scientists teamed up to make sure the high quality of our journal articles, three associate editors are on board, including Prof. Rafael Luque (Universidad de Córdoba), Prof. Tierui Zhang (Technical Institute of Physics and Chemistry, CAS) and Prof. Qiang Zhang (Tsinghua University). The diversity of insights and expertise of this elite editorial team will present our readers with the most

Jinlong Gong

trans_tju@tju.edu.cn

1 Tianjin University, Tianjin, China 
insightful and cutting-edge research achievements and provide authors a highly efficient peer review and publishing production processes. We firmly believe that, with all the efforts of our excellent editorial team, critical reviewers, passionate readers and ingenious authors, Transactions of Tianjin University will evolve into a leading scientific journal in the research field of green and sustainable energy.

Jinlong Gong

Editor in chief

Transactions of Tianjin University

Open Access This article is licensed under a Creative Commons Attribution 4.0 International License, which permits use, sharing, adaptation, distribution and reproduction in any medium or format, as long as you give appropriate credit to the original author(s) and the source, provide a link to the Creative Commons licence, and indicate if changes were made. The images or other third party material in this article are included in the article's Creative Commons licence, unless indicated otherwise in a credit line to the material. If material is not included in the article's Creative Commons licence and your intended use is not permitted by statutory regulation or exceeds the permitted use, you will need to obtain permission directly from the copyright holder. To view a copy of this licence, visit http://creativecommons.org/licenses/by/4.0/.

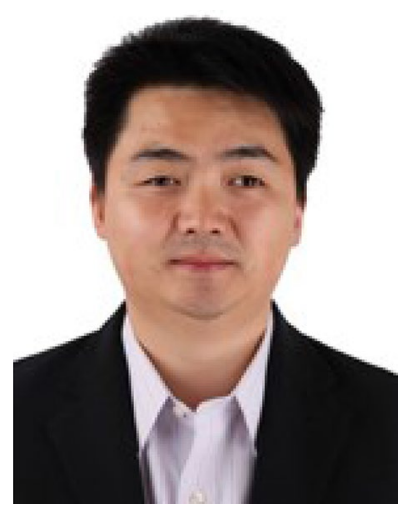

Jinlong Gong studied chemical engineering and received his B.S. and M.S. degrees from Tianjin University and his Ph.D. degree from the University of Texas at Austin under the guidance of C. B. Mullins. After a stint with Professor George M. Whitesides as a postdoctoral research fellow at Harvard University, he joined the faculty of Tianjin University, where he currently holds a Cheung Kong Chair Professorship in chemical engineering. He was a visiting scientist at the Pacific Northwest National Laboratory in 2007. He has served on the editorial boards for several journals including Chemical Society Reviews, Chemical Science, and AIChE Journal. He has also served as an associate editor for ACS Sustainable Chemistry \& Engineering. He is an elected Fellow of the Royal Society of Chemistry. He has published more than 200 papers in peer-refereed journals (with citation over 10000 times and $\mathrm{H}$-index of 53) and been listed as a co-inventor on 67 patents and applications. His research interests in catalysis include catalytic conversions of green energy, novel utilizations of carbon oxides, and synthesis and applications of nanostructured materials. Professor Gong is the Director of the Office of Academic Affairs of Tianjin University. 